\title{
POR UMA NOVA POLÍTICA DE DIREITOS AUTORAIS PARA A AMÉRICA LATINA: O SOFTWARE LIVRE COMO INSTRUMENTO DE EFETIVAÇÃO DO DIREITO ECONÔMICO AO DESENVOLVIMENTO TECNOLÓGICO
}

\section{Túlio Lima Vianna}

Professor de Direito da PUC-MG. Doutorando (UFPR) e Mestre (UFMG) em Direito.

Editor da página www.tuliovianna.org .

e-mail: tuliovianna@pucminas.br

RESUMO: A efetivação do direito econômico ao desenvolvimento tecnológico na América Latina atualmente encontra óbice na política internacional de comercialização de softwares proprietários. Além do elevado custo com as licenças de direitos autorais, tais softwares impedem qualquer adaptação do programa às necessidades locais. Contrapondo-se a este modelo populariza-se o software livre, que concede ao usuário o direito de usar, copiar, modificar e distribuir o programa livremente. A política estadunidense de colonização tecnológica da América Latina baseia-se em duas estratégias: a pressão pela criminalização e repressão à pirataria e a aculturação do mercado consumidor ao software proprietário. O objetivo do combate internacional à pirataria não é evitar o uso de programas comerciais não licenciados nos países emergentes, mas ampliar o mercado consumidor das empresas de software. Do ponto de vista econômico, a migração para o software livre equivale à pirataria e como tal é evitada a todo custo pelas empresas de software, seja através de uma publicidade muitas vezes enganosa ou pela aculturação dos consumidores com a doação de softwares proprietários para escolas e universidades. A adoção prioritária de software livre pelas administrações públicas dos países da América Latina não é mera política econômica de contensão de despesas, mas estratégia de incentivo ao desenvolvimento tecnológico latinoamericano.

PALAVRAS-CHAVE: Software livre. Direito autoral. Direito econômico. Desenvolvimento tecnológico. Administração Pública. América Latina. 


\section{PRESSUPOSTOS CONCEITUAIS}

\subsection{Direito econômico ao desenvolvimento tecnológico}

O surgimento do Direito Econômico no século XX consagrou uma série de direitos fundamentais da pessoa humana, até então relegados a segundo plano: o direito ao meio ambiente, o direito do consumidor, a função social da propriedade e outros com nítido caráter de regulação da atividade econômica. Dentre tais direitos, destaca-se neste início do século XXI, o direito ao desenvolvimento tecnológico cuja efetivação depende de políticas econômicas que incentivem a autonomia científica nacional e a democratização do acesso às novas tecnologias.

Neste contexto, os direitos autorais tornam-se poderosos instrumentos da política econômica de desenvolvimento tecnológico e cultural de um país. Destaca-se dentre estes, os direitos autorais sobre software, não só por sua importância econômica, mas principalmente por sua influência estratégica no desenvolvimento de uma política tecnológica autônoma nos países da América Latina.

\subsection{Software}

O software é uma série de instruções capaz de ser executada por um computador (hardware) para se alcançar um resultado pretendido. ${ }^{1}$

Por analogia, pode-se concebê-lo como uma partitura musical que, quando executada adequadamente em um piano, produz uma série ordenada de sons que entendemos como música. O computador, tal como o piano, é um instrumento criado pelo homem para realizar uma série de funções a serem definidas a posteriori. $O$ programador definirá, ao escrever o software, as operações a serem executadas pelo computador, da mesma forma que um compositor indicará, ao escrever a partitura, os sons a serem executados pelo piano.

Computadores, no entanto, são instrumentos bem mais versáteis que pianos. Há softwares capazes de executarem concertos de Beethoven para piano e, neste caso, o computador será tão-somente um dublê do instrumento, mas há

\footnotetext{
${ }^{1}$ VIANNA, Túlio Lima. Fundamentos de Direito Penal Informático. p.8.
} 
também softwares capazes de processar textos, realizar sofisticados cálculos matemáticos, jogar xadrez, dentre uma infinidade de outras funções.

Como conseqüência de suas múltiplas utilidades, os computadores são instrumentos de valor estratégico bem maior que os pianos, e os softwares possuem valor econômico infinitamente superior.

\subsection{Softwares proprietários}

O proprietário de um piano, por certo, teria muitas despesas se a cada vez que desejasse executar uma nova música em seu instrumento tivesse que pagar direitos autorais ao compositor. Felizmente, na prática, um pianista amador limita-se a copiar a partitura de um livro, revista ou Internet e executá-la em seu instrumento. ${ }^{2}$

O mesmo, no entanto, não se dá em relação à maioria dos softwares, que é comercializada a preços exorbitantes por grandes multinacionais. Algumas destas licenças de software têm valores próximos ao próprio computador. É como se um pianista tivesse que investir o valor de um novo piano em uma partitura musical.

Não bastasse serem caros, os softwares comerciais ainda possuem outro inconveniente: não podem ser modificados pelo usuário. Quando um músico adquire uma partitura para piano, algumas vezes necessita adaptá-la para ser tocada em outro instrumento, como por exemplo, um violão. Esta adaptação é fundamental para que ele consiga tocar a música e, sem ela, ele seria obrigado a adquirir um novo instrumento e aprender a tocá-lo, o que inviabilizaria completamente a execução da obra.

Os programadores, da mesma forma, muitas vezes não dispõem do mesmo equipamento no qual o software foi criado e necessitam fazer pequenas modificações para otimizar determinados programas para serem executados em seus computadores. O modelo do software proprietário, no entanto, não permite qualquer modificação, impedindo seus usuários com conhecimentos técnicos de adaptarem o software às suas necessidades individuais e de detectarem e corrigirem eventuais falhas do programa.

\footnotetext{
2 Art.46, VI, da Lei 9.610/98: "Não constitui ofensa aos direitos autorais: (...) VI- a representação teatral e a execução musical, quando realizadas no recesso familiar ou, para fins exclusivamente didáticos, nos estabelecimentos de ensino, não havendo em qualquer caso intuito de lucro" e Súmula 386 do STF: "Pela execução de obra musical por artistas remunerados é devido direito autoral, não exigível quando a orquestra for de amadores".
} 


\subsection{Software livre}

Contrapondo-se ao modelo do software proprietário, consolida-se a cada dia o modelo do software livre, pelo qual o usuário tem direito de usar, copiar, modificar e distribuir o programa sem qualquer restrição contratual ou legal.

Software Livre (Free Software) é o software disponível com a permissão para qualquer um usá-lo, copiá-lo, e distribuí-lo, seja na sua forma original ou com modificações, seja gratuitamente ou com custo. Em especial, a possibilidade de modificações implica em que o código fonte esteja disponível. Se um programa é livre, potencialmente ele pode ser incluído em um sistema operacional também livre. É importante não confundir software livre com software grátis porque a liberdade associada ao software livre de copiar, modificar e redistribuir, independe de gratuidade. $^{3}$

O uso do software livre não está condicionado ao pagamento de direitos autorais ou à compra de licenças. Assim, qualquer pessoa no mundo pode instalar um software livre em seu computador e usá-lo sem a necessidade de pagamento a quem quer que seja. Paradoxalmente, esta liberdade de acesso ao software livre não exclui a possibilidade de empresas venderem CD-ROMs com software livre, em geral acompanhado de manuais explicativos e um período de suporte técnico. Neste caso, o usuário não pagará pelo software propriamente dito, mas sim, pelos serviços da empresa.

A característica fundamental de um software livre não é, no entanto, o direito ao livre uso, cópia e distribuição, muitas vezes confundido com a simples gratuidade do programa. O mais importante é que o software livre é distribuído com o código fonte aberto, o que permite a programadores a livre modificação do software original e a adaptação do programa às suas necessidades individuais. Esta liberdade de modificação do programa original está condicionada, todavia, à manutenção da licença de software livre para os programas dele derivados. Assim, um programa criado a partir da modificação de um software livre deverá ser obrigatoriamente distribuído como software livre. Esta característica é essencial à preservação do modelo de livre distribuição e impede que alguém se aproprie destes programas de criação coletiva.

\footnotetext{
${ }^{3}$ Roberto A Hexsel. Propostas de Ações de Governo para Incentivar o Uso de Software Livre.
} 
Este modelo de livre distribuição de software ganhou forte impulso com 0 advento e popularização do sistema operacional GNU/Linux e a partir de então, o número de programas distribuídos como softwares livres multiplicou-se. Atualmente, além do sistema operacional GNU/Linux, considerado tecnicamente superior ao Microsoft/Windows em muitos aspectos, há excelentes softwares livres de igual ou superior qualidade aos principais softwares comerciais disponíveis no mercado. Salvo programas bastante específicos, estão disponíveis softwares livres que realizam exatamente as mesmas funções de softwares comerciais, com as vantagens de poderem ser adquiridos gratuitamente e de poderem ser adaptados por um programador a necessidades específicas.

\section{A COLONIZAÇÃo TECNOLÓGICA DA AMÉRICA LATINA}

O mercado mundial de software movimentou cerca de US $\$ 59$ bilhões em 2004. Deste total, US\$ 52 bilhões foram gastos nos países desenvolvidos com a compra de licenças de softwares comerciais contra parcos US $\$ 7$ bilhões nos países emergentes. ${ }^{4}$

Comparado às vendas de hardware nestes países, o mercado de software, contudo, ainda é demasiadamente modesto, o que indica duas possibilidades: a generalização do uso de softwares piratas ou a adoção de software livre.

Em ambas as hipóteses, há um imenso mercado a ser potencialmente explorado pela indústria de software estadunidense, em especial na América Latina, onde a demanda tecnológica é bastante significativa.

A política colonial da indústria de software estadunidense para a América Latina se desenvolve a partir de duas estratégias bastante definidas: a pressão pela criminalização e repressão à pirataria e a aculturação dos consumidores ao software proprietário.

\subsection{A criminalização e repressão à pirataria}

As pesquisas patrocinadas pelas entidades internacionais de proteção ao direito do autor parecem desconsiderar a existência do software livre. Em suas metodologias, optam simplesmente por considerarem como software pirata todo 
aquele que não foi comprado. Com base em tais pressupostos, concluem que a indústria de software teve prejuízos de US\$1,4 bilhão de dólares na América Latina em $2004^{5}$

Estes números, apurados com base em metodologia de pesquisa no mínimo duvidosa, fundamentam pressões internacionais que ameaçam os países da América Latina com sanções econômicas caso a pirataria não seja devidamente criminalizada e reprimida.

A política estadunidense de pressões contra a pirataria no mundo é coordenada pela United States Trade Representative (USTR) que divulga anualmente a sua "Priority Watch List" na qual elenca os países em que a pirataria encontra-se mais difundida no mundo. O rol divulgado em junho de 2005 aponta três países da América Latina: Venezuela, com 79\% de softwares piratas em 2004, Argentina, com 75\%, e Brasil, com 64\%.

Em relação ao Brasil o relatório da USTR de 2004 afirmava que:

O Brasil é um dos maiores mercados do globo para se legitimar produtos com direitos autorais, mas também um dos maiores mercados da pirataria. $A$ pirataria de mídia óptica e a pirataria de Internet estão aumentando. As estimativas da indústria de direitos autorais dos Estados Unidos é de que as perdas no Brasil são as maiores no hemisfério, com perdas estimadas pela indústria de mais de US\$785 milhões em $2003 .^{6}$

Está claro que o objetivo do governo dos Estados Unidos não é simplesmente acabar com a pirataria, mas ampliar o mercado consumidor de sua indústria de softwares proprietários. As campanhas de conscientização contra a pirataria limitam-se a defender a legalização dos produtos piratas, através da compra de licenças e jamais mencionam a possibilidade da migração para software livre, que pode ser baixado gratuitamente pela Internet.

4 BSA. Segundo estudo global anual sobre pirataria de software da BSA-IDC.

5 IIPA International Intellectual Property Alliance. 2003-2004 Final estimated trade losses due to copyright piracy and piracy levels in-country: the Americas.

6 "Brazil is one of the largest markets globally for legitimate copyrighted products, but also one of the world's largest pirate markets. Optical media piracy and Internet piracy are increasing. The U.S. copyright industry estimates that losses in Brazil are the largest in the hemisphere, with industry-estimated losses exceeding \$785 million in 2003". USTR United States Trade Representative. Special 301 Priority Watch List. 
Ao contrário do que deseja fazer crer as estatísticas estadunidenses, a indústria de software não perde US\$785 milhões com a pirataria, mas sim, deixa de lucrar estes valores por não ter conquistado ainda este mercado. O mais provável é que, mesmo com a repressão à pirataria, nunca se chegue a estes valores, pois grande parte dos atuais usuários de programas piratas, certamente migrará para softwares livres caso se sintam coagidos a abandonarem a ilegalidade.

\subsection{Aculturação dos consumidores ao software proprietário}

Além da repressão à pirataria patrocinada pelas associações de proteção aos direitos autorais, com o apoio do governo dos Estados Unidos, as multinacionais de software procuram expandir seus mercados a partir de uma aculturação de consumidores de países emergentes.

Para tanto, investem massivamente em publicidade para a divulgação de seus produtos e para desestimular não só a pirataria, mas também o uso de software livre. Esta publicidade não se limita à conscientização dos usuários sobre a ilegalidade da pirataria, mas busca iludi-los com propagandas mentirosas de que produtos piratas podem estragar o equipamento ou disseminar vírus.

A publicidade contra o software livre, por outro lado, procura valer-se do monopólio de mercado dos softwares proprietários, alegando que a migração para o software livre ocasionaria incompatibilidades na troca de arquivos com usuários que adotassem os softwares proprietários. Além disso, chegaram ao cúmulo de defender a tese de que o software livre tem custo mais alto para as empresas que o software proprietário:

A atratividade do software livre é acelerar o desenvolvimento de plataformas de código aberto, mas código aberto não é gratuito e pode realmente acrescentar risco financeiro e comercial. As discussões com cinco companhias que investigaram seu custo total indicaram que Linux é entre $5 \%$ e $20 \%$ mais caro que Windows. ${ }^{7}$

Uma análise atenta da metodologia adotada na pesquisa esclarece, no entanto, que tais conclusões foram obtidas superestimando-se os valores gastos com manutenção e suporte técnico nas plataformas de software livre e simplesmente 
desconsiderando que o software proprietário também necessita de suporte. Frise-se ainda que tais resultados foram obtidos com base em amostragem demasiadamente pequena para validar as conclusões do estudo.

Não obstante a duvidosa metodologia da pesquisa, estes resultados foram alardeados pela mass media não só em anúncios publicitários, mas também em matérias jornalísticas visivelmente tendenciosas em prol de softwares proprietários, muitos deles anunciantes das publicações.

Além desta publicidade enganosa, a indústria do software busca aculturar potenciais consumidores, doando licenças para escolas e universidades. Os estudantes aprendem a operar computadores por meio de softwares proprietários e, quando profissionais, passam a oferecer resistência à migração ao software livre, que os obrigariam a uma reciclagem profissional. Por um longo período, as multinacionais do software toleraram a pirataria em países emergentes como forma de aculturar o mercado e, só recentemente, passaram a pressionar o governo destes países para fazer valer as leis de proteção aos direitos autorais.

\section{SOFTWARE LIVRE NA AMÉRICA LATINA}

A idéia da adoção de software livre em computadores da administração pública não é recente. Já em 2001, Cynthia Semíramis defendia esta proposta, não só pela diminuição dos custos e pela flexibilidade na adaptação do código às necessidades dos órgãos públicos, mas também como medida de garantia de segurança das informações processadas pelos computadores estatais. ${ }^{8}$

Na América Latina, o Peru foi o pioneiro em projetos de leis para a adoção de software livre na administração pública. O projeto de lei no 1.609 de 14 de dezembro de 2001, propunha a obrigatoriedade do uso de softwares livres nos computadores de todos os órgãos da administração pública peruana. Este projeto não teve êxito, mas uma nova tentativa foi feita com o projeto de lei no 2.485 de 8 de abril de 2002 que ratificava a proposta inicial.

\footnotetext{
7 "The allure of free software is accelerating the deployment of open source platforms, but open source is not free and may actually increase ?nancial and business risk. Discussions with ?ve companies that tracked their total costs indicated Linux was between $5 \%$ and $20 \%$ more expensive than Windows." GIERA, Julie. BROWN, Adam. The costs and risks of open source: debunking the myths. p. 2.

8 MACHADO, Cynthia Semíramis Figueiredo. Software e Privacidade: uma defesa do código-fonte aberto na preservação do direito constitucional à vida privada. p.90
} 
A Microsoft, maior multinacional de software do mundo, reagiu rapidamente e doou US\$550.000 em dinheiro, softwares e serviços de consultoria ao governo peruano, conseguindo assim conter a iniciativa.

Esta lei provocou, há apenas quatro meses, uma resposta imediata da Microsoft em que expunha sua oposição e disparava contra o software livre. Também o presidente Bush pressionou contra o projeto de lei do software livre no Peru por meio de seu embaixador Hamilton. ${ }^{9}$

$\mathrm{Na}$ Argentina, em 2002, foi proposto um projeto de lei com a finalidade de incentivar a adoção de software livre pelo governo. ${ }^{10} \mathrm{O}$ projeto não foi aprovado e, em 2004, um novo projeto de lei foi enviado ao congresso com o mesmo objetivo. ${ }^{11}$

No Brasil, a priorização do software livre pela administração pública federal se deu a partir do decreto presidencial de 29 de outubro de 2003 que instituiu os comitês técnicos do Comitê Executivo do Governo Eletrônico. ${ }^{12} \mathrm{~A}$ iniciativa do poder executivo brasileiro mostrou-se ser bem mais eficiente que as congêneres oriundas do poder legislativo dos países vizinhos.

Seguindo a estratégia brasileira, a Venezuela também optou por priorizar o software livre por meio de decreto presidencial em 23 de dezembro de $2004 .^{13}$

O sucesso da iniciativa brasileira provocou grande debate sobre a adoção prioritária de software livre pelos governos dos países latino-americanos e em maior ou menor grau todos os países do continente já estudam a proposta.

\section{4 À GUISA DE CONCLUSÃo}

A controvérsia sobre a adoção prioritária de software livre nos computadores da administração pública dos países da América Latina tende a aumentar com as crescentes pressões internacionais. A indústria de software internacional procura desesperadamente conquistar mercados consumidores para seus produtos,

9 "Esta ley provocó hace apenas cuatro meses una respuesta inmediata de Microsoft en la que planteaba su oposición y despotricaba en contra del software libre. También el Presidente Bush presionó en contra del Proyecto de Ley de software libre en Perú por medio de su embajador Hamilton." BAQUIA. Microsoft dona 550.000 dólares al gobierno peruano.

\footnotetext{
${ }^{10}$ ARGENTINA. Proyecto de Ley 904-D-02 (Dragan, Becerra y Bertone).

${ }^{11}$ ARGENTINA. Proyecto de Ley 1280-D-04 (Cantini).

12 BRASIL. Decreto de 29 de outubro de 2003.

${ }^{13}$ VENEZUELA. Decreto n³.390 de 23 de diciembre de 2004.
} 
substituindo a prática da pirataria pela legalização dos atuais softwares proprietários com a compra das respectivas licenças.

Tal solução apresenta-se, porém, como demasiadamente dispendiosa para a realidade econômica da América Latina. Com a crescente sofisticação tecnológica dos softwares livres é mais provável e recomendável que os usuários latinoamericanos substituam seus programas proprietários, ainda que legalizados, por softwares livres, já que estes permitem atualizações gratuitas para versões mais modernas e seguras. Esta política trará benefícios econômicos substanciais, diminuindo gastos com importações. No Brasil, as estimativas indicam valores expressivos que seriam economizados caso governo, empresas e usuários domésticos venham a adotar o software livre:

Supondo custos operacionais semelhantes entre proprietário, e não proprietário 0 não pagamento de licenças pode significar uma economia de cerca de $R \$ 800,00$ por desktop e de cerca de $R \$ 2.000,00$ em média por servidor, o que levaria a uma economia de cerca de $R \$ 85$ milhões/ano. Se considerarmos que alguns pacotes de Linux hoje comercializados trazem ainda 0 MS-Office e mais um conjunto de outros softwares, este valor tende a se multiplicar por cerca de 10 vezes. $^{14}$

A adoção de software livre pelos governos, não só em repartições públicas, mas principalmente em escolas e universidades é o primeiro passo de uma estratégia de longo prazo para a emancipação tecnológica da América Latina.

O software proprietário impede a criação e desenvolvimento de tecnologia nacional, ao impossibilitar a modificação dos programas de acordo com as necessidades regionais. Sua adoção na América Latina só interessa às multinacionais do software e seus países-sede, interessados no dinheiro derivado das exportações de licenças.

O software livre, por outro lado, é um produto apátrida ou, melhor dizendo, universal. É desenvolvido cooperativamente por milhares de programadores em todo o mundo, podendo ser modificado livremente de acordo com necessidades locais. Tal característica permite o desenvolvimento de aplicações voltadas para a realidade latino-americana, bem como a autonomia tecnológica em relação aos países desenvolvidos.

Do ponto de vista econômico, o software livre não tem custos com direitos autorais e os gastos são limitados aos serviços de instalação e manutenção dos 
sistemas. O dinheiro movimentado, no entanto, tende a permanecer no próprio país, incentivando a criação de emprego e o treinamento de mão-de-obra extremamente qualificada.

A adoção do software livre é corolário do direito econômico ao desenvolvimento tecnológico consagrado no art. 218 da Constituição Brasileira e seu implemento nos demais países latino-americanos é não só recomendável, mas uma necessidade para uma efetiva emancipação tecnológica da América Latina.

\section{REFERÊNCIAS BIBLIOGRÁFICAS}

ARGENTINA. Proyecto de Ley 1280-D-04 (Cantini). Disponível em: http://proposicion.org.ar/ proyecto/leyes/1280-D-04/index.html.es . Acesso em 10 de junho de 2005.

ARGENTINA. Proyecto de Ley 904-D-02 (Dragan, Becerra y Bertone). Disponível em: http://proposicion.org.ar/proyecto/leyes/904-D-02/index.html.es . Acesso em 10 de junho de 2005.

BAQUIA. Microsoft dona 550.000 dólares al gobierno peruano. 16 de julho de 2002. Disponível em: http://www.baquia.com/noticias.php?idnoticia=00001.20020716 . Acesso em 10 de junho de 2005.

BRASIL. Decreto de 29 de outubro de 2003. Institui Comitês Técnicos do Comitê Executivo do Governo Eletrônico e dá outras providências. Disponível em: http://www.softwarelivre.gov.br/ documentos/DecretoComite/view. Acesso em 9 de junho de 2005.

BRASIL. Softwarelivre.gov.br. Disponível em: http://www.softwarelivre.gov.br/ Acesso em 8 de junho de 2005.

BSA. Segundo estudo global anual sobre pirataria de software da BSA-IDC. Maio de 2005. 16p. Disponível em:

${ }^{14}$ SOFTEX. O impacto do software livre e de código aberto na indústria de software do Brasil. p.69. 
http://www.bsa.org/globalstudy/loader.cfm?url=/commonspot/security/getfile.cfm\& pageid=24479\&hitboxdone=yes . Acesso em 8 de junho de 2005 .

GIERA, Julie. BROWN, Adam. The costs and risks of open source: debunking the myths. Cambridge: Forrester, 12 de abril de 2004. 16p. Disponível em: http://download.microsoft.com/ download/7/d/0/7d059de9-1557-415c-8332920db6f89e44/FRSTRossCosts0404.pdf . Acesso em 9 de junho de 2005.

GNU. Proyectos ley software libre en la administración pública del gobierno peruano Congreso de la Republica. Disponível em: http://www.gnu.org.pe/proleyap.html . Acesso em 10 de junho de 2005.

HEXSEL, Roberto A. Propostas de Ações de Governo para Incentivar o Uso de Software Livre. Relatório Técnico do Departamento de Informática da UFPR, 004/2002, Curitiba: UFPR, outubro de 2002. 53p. Disponível em: http://www.inf.ufpr.br/info/techrep/RT_DINF004_2002.pdf . Acesso em 8 de junho de 2005.

IIPA International Intellectual Property Alliance. 2005 Special 301 Report: Brazil. 18p. Disponível em: http://www.iipa.com/rbc/2005/2005SPEC301BRAZIL.pdf . Acesso em 8 de junho de 2005.

IIPA International Intellectual Property Alliance. 2003-2004 Final estimated trade losses due to copyright piracy and piracy levels in-country: the Americas. $1 \mathrm{p}$. Disponível em: http://www.iipa.com/pdf/IPA\%20USTR\%202005\%20SPECIAL\%20301\%20DECISIO NS\%20with\%20revised\%20BSA\%20figures\%20for\%20the\%20Americas\%20060405. pdf . Acesso em 8 de junho de 2005.

INTERNATIONAL Institute of Infonomics. Free/Libre and Open Source Software. Disponível em: http://flossproject.org/ . Acesso em 10 de junho de 2005.

MACHADO, Cynthia Semíramis Figueiredo. Software e Privacidade: uma defesa do código-fonte aberto na preservação do direito constitucional à vida privada. In: CERQUEIRA, Tarcísio Queiroz, IRIARTE, Erick, PINTO, Márcio Morena (Coord.). Informática e Internet. Aspectos legais internacionais. Rio de Janeiro: Esplanada, 2001. 386p. 
MÉXICO. Análisis sobre la factibilidad del uso de FLOSS en los gobiernos. Disponível em: http://www.softwarelibre.gob.mx/ . Acesso em 10 de junho de 2005.

SOFTEX. O impacto do software livre e de código aberto na indústria de software do Brasil. Campinas: Softex, 2005. 76 p. Disponível em: http://www.softex.br/media/Pesquisa_Impacto_SL-CA_na_industria_sw_brasileira.zip . Acesso em 9 de junho de 2005.

USTR United States Trade Representative. Special 301 Priority Watch List. Disponível em: http://www.ustr.gov/Document_Library/Reports_Publications/2004/2004_Special_301 /Special_301_Priority_Watch_List.html. Acesso em 8 de junho de 2005.

VENEZUELA. Decreto $n^{\circ} 3.390$ de 23 de diciembre de 2004. Disponível em: http://www.gobiernoenlinea.gob.ve/docMgr/sharedfiles/Decreto3390.pdf . Acesso em 10 de junho de 2005.

VIANNA, Túlio Lima. Fundamentos de direito penal informático: do acesso não autorizado a sistemas computacionais. Rio de Janeiro: Forense, 2003. 170p. 